\title{
Synergistic Effect of Potassium Iodide with L-Tryptophane on the Corrosion Inhibition of Mild Steel: A Combined Electrochemical and Theoretical Study
}

\author{
Lei Guo ${ }^{1, *}$, Guang Ye ${ }^{1}$, Ime Bassey Obot ${ }^{2}$, Xiaohong Li $^{1}$, Xun Shen ${ }^{1}$, Wei Shi ${ }^{1}$, Xingwen Zheng ${ }^{3}$ \\ ${ }^{1}$ School of Material and Chemical Engieering, Tongren University, Tongren 554300, China \\ ${ }^{2}$ Center of Research Excellence in Corrosion, King Fahd University of Petroleum and Minerals, \\ Dhahran 31261, Saudi Arabia \\ ${ }^{3}$ Material Corrosion and Protection Key Laboratory of Sichuan province, Zigong 643000, China \\ *E-mail: cqglei@163.com
}

doi: $10.20964 / 2017.01 .04$

Received: 30 September 2016 / Accepted: 8 Nobember 2016 / Published: 12 December 2016

The inhibition effects of L-tryptophane (Trp) and its synergistic effect with KI on the corrosion of mild steel in $1.0 \mathrm{M} \mathrm{HCl}$ solution have been investigated by electrochemical impedance spectroscopy (EIS) and potentiodynamic polarization (PDP) measurements. The results show that the inhibition efficiency increases with the concentration of Trp and increases further when KI exists. The synergistic effect between Trp and KI was discussed by calculating the synergism parameter, which suggests that there is a cooperative mechanism between iodide anion and Trp cation. Finally, Monte Carlo simulation was utilized to search for the equilibrium configurations of inhibitors/ $\mathrm{Fe}(110)$ adsorption systems in the presence of water molecules.

Keywords: L-tryptophane, Corrosion inhibitor, Mild steel, Theoretical calculations, Electrochemical investigation

\section{FULL TEXT}

(C) 2017 The Authors. Published by ESG (www.electrochemsci.org). This article is an open access article distributed under the terms and conditions of the Creative Commons Attribution license (http://creativecommons.org/licenses/by/4.0/). 